\title{
Male solitary drinking and hazardous alcohol use in nine countries of the former Soviet Union
}

\author{
Andrew Stickley ${ }^{\mathrm{a}, \mathrm{b}, \mathrm{c}, *}$, Ai Koyanagi ${ }^{\mathrm{d}, \mathrm{e}}$, Bayard Roberts $^{\mathrm{a}}$, Adrianna Murphy ${ }^{\mathrm{a}}$, \\ Kseniya Kizilova ${ }^{\mathrm{f}}$, Martin McKee ${ }^{\mathrm{a}}$ \\ a European Centre on Health of Societies in Transition, London School of Hygiene and Tropical Medicine, London, United Kingdom \\ b Stockholm Centre on Health of Societies in Transition (SCOHOST), Södertörn University, Huddinge, Sweden \\ ' Department of Human Ecology, Graduate School of Medicine, University of Tokyo, Tokyo, Japan \\ ${ }^{\mathrm{d}}$ Research and Development Unit, Parc Sanitari Sant Joan de Déu, Fundació Sant Joan de Déu, Sant Boi de Llobregat, Barcelona, Spain \\ e Instituto de Salud Carlos III, Centro de Investigación Biomédica en Red de Salud Mental, CIBERSAM, Madrid, Spain \\ ${ }^{\mathrm{f}}$ Social and Humanitarian Research Institute, V.N. Karazin Kharkov National University, Kharkiv, Ukraine
}

\section{A R T I C L E I N F O}

\section{Article history:}

Received 30 November 2014

Received in revised form 8 February 2015

Accepted 14 February 2015

Available online 25 February 2015

\section{Keywords:}

Solitary drinking

Former Soviet Union

Alcohol problems

Heavy episodic drinking

HITT survey

\begin{abstract}
A B S T R A C T
Background: Despite evidence that many people engage in solitary drinking and that it might be associated with negative consequences, to date, little research has focused on this form of drinking behaviour. This study examined the prevalence and factors associated with solitary drinking, and assessed whether it is linked with hazardous alcohol use among males in nine countries of the former Soviet Union (fSU).

Methods: Data came from a cross-sectional population-based survey undertaken in 2010/11 in Armenia, Azerbaijan, Belarus, Georgia, Kazakhstan, Kyrgyzstan, Moldova, Russia, and Ukraine. Information was obtained on the frequency of solitary drinking among male regular drinkers (i.e., those consuming alcoholic drinks at least once a month), and on problem drinking (CAGE) and heavy episodic drinking (HED). Logistic regression analysis was used to examine associations between the variables.

Results: The prevalence of occasional and frequent solitary drinking ranged from $8.4 \%$ (Georgia) to $42.4 \%$ (Azerbaijan), and 3.1\% (Kazakhstan) to 8.2\% (Armenia), respectively. Solitary drinking was associated with being older, divorced/widowed, living alone, having a bad/very bad household financial situation, lower levels of social support, and poor self-rated health. Occasional solitary drinking was linked to problem drinking and HED, while frequent solitary alcohol use was related to problem drinking.

Conclusions: Solitary drinking is relatively common among male regular drinkers in the fSU and is linked to older age, social and economic disadvantage, and hazardous alcohol use.
\end{abstract}

(c) 2015 Elsevier Ireland Ltd. All rights reserved.

\section{Introduction}

An important factor in the occurrence of drinking is the context or situation in which alcohol consumption takes place (Greenfield and Room, 1997), including whether drinking occurs in the presence of others or while alone (Cox and Klinger, 1988). It has been suggested that drinking while alone might be related to differences in drinking motives (Cooper et al., 1992), and drinking frequency (Demers and Bourgault, 1996), while some research has linked solitary drinking with negative alcohol-related

\footnotetext{
* Corresponding author at: Stockholm Centre on Health of Societies in Transition (SCOHOST), Södertörn University, 14189 Huddinge, Sweden. Tel.: +46 8608 4689; fax: +4686083040.

E-mail address: andrew.stickley@sh.se (A. Stickley).
}

behaviours and outcomes such as hazardous drinking and alcohol dependence (Assanangkornchai et al., 2000; Gaunekar et al., 2005). Despite this, to date, there has been very little research specifically focused on solitary drinking, possibly because alcohol consumption is regarded as a normative social activity. For example, little is known about the prevalence of solitary drinking within and between populations even though some research indicates that this practice might be widespread. A recent study has shown that in the period from 1968 to 2008, across six study time points, between $14-24 \%$ of men and $8-13 \%$ of women aged 15-69 years reported drinking alone at home in Finland (Mäkelä et al., 2012). Findings from other studies undertaken in North America have produced even higher figures, indicating that over 30\% of adults (Bourgault and Demers, 1997) and adolescents (Creswell et al., 2014) may drink alone at some point in time. 
There is also little information about factors that are associated with solitary drinking among the general adult population as previous studies have tended to focus on specific groups such as college students (Christiansen et al., 2002; Gonzalez, 2012; Gonzalez et al., 2009). The limited research undertaken among broader age groups to date has produced conflicting findings, which is not surprising given that this behaviour is likely to be shaped by one's social context. Older individuals were more likely to drink alone at home in Denmark (Grønkjær et al., 2010), but no statistically significant associations between age and solitary drinking were found in Montreal, Canada (Demers and Bourgault, 1996). Information is also lacking on the extent to which social and/or economic factors are associated with solitary drinking. The study in Montreal linked factors such as employment status (looking for a job) and living alone to solitary drinking (Demers and Bourgault, 1996). However, the correlates of solitary drinking in different contexts remain unknown.

Data on the association between solitary drinking and harmful drinking and alcohol misuse are also comparatively scarce, especially in the general population. Given the perception of alcohol consumption as a social activity, there has been a tendency to regard solitary drinking as a more pathological (Bourgault and Demers, 1997) and problematic (Grønkjær et al., 2013) form of drinking behaviour. For example, in a study undertaken in seven European countries in 2010/11, becoming intoxicated when alone was more widely identified as a form of alcohol abuse than when doing so in the company of others (Nordlund and Østhus, 2013). The Montreal study found however, that for most of its adult participants, solitary drinking was associated with moderate alcohol use (Demers and Bourgault, 1996) and that only those solitary drinkers who engaged in heavy drinking (five or more drinks per occasion) were more likely to have alcohol-related problems (Bourgault and Demers, 1997). A study among college students also found that solitary heavy drinkers were more likely to have alcohol problems than social heavy drinkers (Gonzalez et al., 2009). Other studies have indicated that solitary drinking might be linked to higher alcohol consumption (Martin and Casswell, 1987), especially among some (e.g., ethnic) groups (Neff, 1997).

One area of the world where there has been almost no research on individual drinking situations is in the countries of the former Soviet Union (fSU), which have some of the highest levels of population alcohol consumption globally (World Health Organization, 2011). The detrimental effects of alcohol on population well-being have been extensively documented in this region in the past fifteen years (Leon et al., 2007; Stickley et al., 2007; Zaridze et al., 2014). Importantly, recent research has highlighted how aspects of the social environment such as social isolation and loneliness (Murphy et al., 2014a; Stickley et al., 2013) are linked to hazardous alcohol use in this setting. As earlier Western research has connected solitary drinking to similar social-environmental factors (i.e., living alone; Demers and Bourgault, 1996), it is possible that solitary drinking might also be important in this setting and/or linked to alcohol misuse.

Thus, the objective of this study was to gain knowledge on solitary drinking in nine countries of the fSU. While conceiving of solitary drinking as "a specific drinking context, characterised by the lack of a companion and therefore the lack of social control when drinking" (Bourgault and Demers, 1997), the study had three aims: (1) to determine the prevalence of solitary drinking; (2) to examine what factors are associated with solitary drinking; and (3) to explore whether solitary drinking is associated with hazardous alcohol use. Information on the prevalence of solitary drinking, its correlates, and whether it is associated with hazardous alcohol use may be important in future public health efforts to reduce alcohol's detrimental effects on population health and well-being in these countries.

\section{Methods}

\subsection{Study participants}

The data in this study came from the Health in Times of Transition (HITT) survey. This was a nine country cross-sectional survey undertaken in Armenia, Azerbaijan, Belarus, Georgia, Kazakhstan, Moldova, Russia, and Ukraine in 2010 and in Kyrgyzstan in early 2011 (due to political instability). In each country, stratified multi-stage random sampling was employed to obtain a nationally representative household sample. Households were selected by random route procedures from within each primary sampling unit (about 100-200 per country). From within each household one person aged 18 or above was randomly chosen to participate (determined by the nearest birthday). Trained interviewers conducted face-to-face interviews in the respondents' homes using a standard questionnaire. Except for in Russia and Belarus where Russian language was used, all respondents had the choice of answering in either their country languages or Russian.

In total, information was collected from 18,000 respondents. In six of the nine countries, the sample size was 1800 respondents. The exceptions were in Russia $(N=3000)$ and Ukraine $(N=2000)$ which had larger sample sizes to reflect their larger and more regionally diverse populations. Georgia also had a larger sample size $(N=2200)$ as a result of a booster survey of 400 additional interviews which was undertaken in late 2010 to ensure a more representative sample. Response rates varied across the countries from $47 \%$ in Kazakhstan to $83 \%$ in Georgia (Roberts et al. 2013). This study was approved by the ethics committee of the London School of Hygiene and Tropical Medicine and was carried out in accordance with the Helsinki Declaration.

\subsection{Measures}

Frequency of solitary drinking was assessed by the question "How often do you drink alone?". Those who answered never, sometimes and often were classified as never, occasional, and frequent solitary drinkers, respectively. The HITT survey employed a filter option for the first alcohol consumption question which meant that the information collected on solitary drinking refers to those who drank alcohol at least once per month.

Demographic and socioeconomic variables: Respondents were divided into five age categories: $18-29,30-39,40-49,50-59$ and $\geq 60$ years. For education, respondents were classified as having either a 'tertiary education' (complete and incomplete higher education), a 'secondary education' (different forms of secondary education had been completed), or 'less than a secondary education' (incomplete secondary education/primary education/no education). Marital status was categorised as 'married/cohabiting', 'never married' and 'divorced/widowed'. Following the lead of an earlier study that used HITT survey data (Footman et al., 2013), respondents' household economic situation was assessed by the question "How would you describe the economic situation of your household at the present time?" where responses were categorised as 'good/very good', 'average' or 'bad/very bad'. In terms of living arrangements, respondents who reported that they were the only person constantly living in their household were categorised as living alone. Information on the level of respondents' social support was obtained from five questions which enquired if the respondent had anyone who would 'listen to them when they needed to talk', who they could 'count on to help them out in a crisis,' etc. For each of the questions, respondents could answer 'yes' (scored 1) or 'no' (scored 0 ). The scores from the five questions were summed to create a score running from 0 to 5 . The scores were then categorised as 'high' (a score of 4-5), 'moderate (2-3) and 'low' $(0-1)$. For self-rated health, respondents were asked, "In general would you say your health is. .." with five response categories that ranged from 'very good' to 'very poor'. Responses were divided into three categories, 'good/very good', 'fair' and 'poor/very poor'. Finally, for location, respondents were categorised as living in either urban or rural areas.

Hazardous drinking: Following the lead of recent studies that have used HITT data (Murphy et al., 2014a,b), hazardous drinking was measured using two variables. The first was a measure of problematic drinking derived from the CAGE questionnaire. This asks four questions about the degree to which respondents feel the need to cut down on drinking, feel annoyance at being criticised for drinking too much, fee guilty about drinking too much or have had a drink first thing in the morning to steady nerves or get rid of a hangover. Yes (scored 1) and no (scored 0 ) answers were summed to generate a score running from 0 to 4 (Cronbach's alpha $=0.75$ ). A score of 2 or more is employed as a marker of alcohol dependence (Murphy et al. 2014b) and was used as the cut-off score to denote problematic alcohol use. The second measure was heavy episodic drinking (HED). The rapid ingestion of a large quantity of alcohol in a single sitting is a drinking pattern that has a long history in the countries in this region and has been associated with alcohol-related harm (Andreev et al., 2013; Stickley et al., 2009). In the current study, we adopted the definition used by Pomerleau et al. (2008) who, when previously examining HED in 


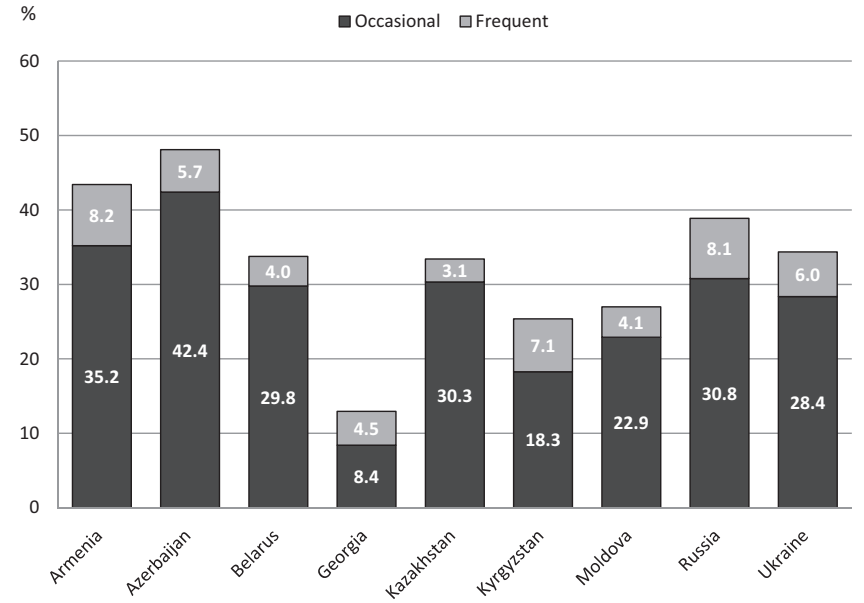

Fig. 1. Prevalence (\%) of occasional and frequent solitary drinking among male regular drinkers in the nine countries of the former Soviet Union ${ }^{1}$.

the countries in this region, defined it as consuming either: $\geq 21$ of beer, $\geq 750 \mathrm{~g}$ of wine, or $\geq 200 \mathrm{~g}$ of strong spirits on one occasion.

\subsection{Statistical analysis}

An initial inspection of the data showed that there were very few female frequent solitary drinkers. For example, no females reported frequent solitary drinking in Azerbaijan and Kazakhstan, and only 2 and 3 cases were observed in Russia and Armenia, respectively. As we wanted to examine if there were any differences between occasional and frequent solitary drinkers, the current study is confined to men. In the first stage of the analysis, we calculated the proportions of never, occasional, and frequent solitary drinking with $95 \%$ confidence intervals by the characteristics of the study sample. Univariable and multivariable logistic regression analyses were then used to assess the factors associated with solitary drinking. We used occasional or frequent solitary drinking as the outcome in separate models with never solitary drinking as the reference category. In the analysis where the outcome was occasional solitary drinking, frequent solitary drinkers were excluded from the analysis, and where the outcome was frequent solitary drinking, occasional solitary drinkers were excluded. In the univariable model, we examined the association between occasional or frequent solitary drinking (dependent variable) and age, education, marital status, household economic situation, living alone, social support, self-rated health, location, and country (independent variables). The selection of these variables was based, in part, on past literature (Demers and Bourgault, 1996). The multivariable model adjusted for all of the covariates. For country, the reference category was the grand mean of all the countries. We also examined the relation between problematic alcohol use or HED (dependent variables) and the frequency of solitary drinking (independent variable) using univariable and multivariable logistic regression analyses. Results are presented in the form of odds ratios (OR) with $95 \%$ confidence intervals (CI). The statistical analysis was performed with Stata 12.1 (Stata Corp LP, College station, Texas). The level of statistical significance was set at $p<0.05$.

\section{Results}

After the exclusion of females, the sample size was 7829. A further 4008 males were excluded as they drank less than once a month, and 105 males were excluded as they were missing information on solitary drinking. Thus, the analytical sample consisted of 3716 men who drank at least once a month (Armenia 304, Azerbaijan 158, Belarus 527, Georgia 464, Kazakhstan 389, Kyrgyzstan 197, Moldova 489, Russia 705, Ukraine 483). The overall prevalence of occasional and frequent solitary drinking was $26.6 \%$ and $5.6 \%$, respectively. The country prevalences of solitary drinking are presented in Fig. 1. The overall prevalence of solitary drinking ranged from $12.9 \%$ (Georgia) to $48.1 \%$ (Azerbaijan), and the prevalence of occasional and frequent solitary drinking ranged from

\footnotetext{
${ }^{1}$ Frequency of solitary drinking was assessed by the question "How often do you drink alone?" and those who answered sometimes and often were classified as occasional and frequent solitary drinkers, respectively.
}

8.4\% (Georgia) to $42.4 \%$ (Azerbaijan), and 3.1\% (Kazakhstan) to $8.2 \%$ (Armenia), respectively.

Details of the frequency of solitary drinking by sample characteristics are presented in Table 1. Frequent solitary drinking was more widespread among those with low social support (15.4\%), age $\geq 60$ years (14.4\%), and the divorced or widowed (14.3\%). The factors associated with occasional and frequent solitary drinking are shown in Table 2. In the adjusted models, older age was associated with higher odds for both frequencies of solitary drinking, with the odds for frequent solitary drinking being especially high among those aged $\geq 60$ years compared to those aged $18-29$ years (odds ratio [OR]: 3.38 ; 95\% confidence interval [CI]: 1.80-6.33). Education was not associated with solitary drinking, while the effects of marital status varied by drinking category: being divorced/widowed increased the odds for occasional solitary drinking (OR: $1.50, \mathrm{CI}$ : 1.10-2.05), while those who had never been married had lower odds for frequent solitary drinking (OR: 0.32 , CI: 0.15-0.68), compared to individuals who were married or cohabiting. Having a bad/very bad household economic situation was associated with significantly higher odds for both occasional and frequent solitary drinking compared to having a good/very good economic situation, while less than a high level of social support was strongly associated with frequent solitary drinking. Living alone was significantly associated with occasional and frequent solitary drinking in the univariable analysis but these relationships were attenuated in the multivariable analysis and became of borderline significance. Having poor/very poor or fair self-rated health was associated with significantly higher odds for occasional solitary drinking but was not associated with frequent solitary drinking. Location (urban/rural residence) was not linked to either form of solitary drinking. When compared to the grand mean of all countries, there were significantly higher odds for occasional solitary drinking in Armenia, Azerbaijan, and Kazakhstan, whereas Georgia, Kyrgyzstan, and Moldova had lower odds. The odds for frequent solitary drinking were significantly higher in Armenia, and Russia, but lower in Georgia and Moldova. In addition, due to the potential colinearity between marital status and living alone (i.e., the widowed/divorced may be more likely to live alone) we conducted several sensitivity analyses. Two fully-adjusted models which separately excluded one of the two variables were constructed. When living alone was excluded, compared to those who were married/cohabiting, individuals who were divorced/widowed had higher odds for both occasional (OR: 1.73, CI: 1.32-2.28, $p<0.001$ ) and frequent solitary drinking (OR: $1.87, \mathrm{CI}: 1.21-2.90, p=0.005$ ). The corresponding figures for living alone when marital status was excluded were 1.72 (CI: $1.26-2.35 p=0.001)$ and 2.14 (CI: $1.30-3.53 p=0.003)$, respectively.

The association between the frequency of solitary drinking and problem drinking or HED is presented in Table 3. In the adjusted model, occasional and frequent solitary drinkers had ORs of 2.08 and 3.27 for problematic alcohol use, respectively. Occasional (OR: 1.25 ) but not frequent solitary drinkers had significantly higher odds for engaging in HED.

\section{Discussion}

This study examined solitary drinking among men who consume alcohol at least once a month in nine countries of the fSU. It has shown that solitary drinking occurs among a sizeable number of regular drinkers in nearly every country with the prevalence of solitary drinking ranging from $12.9 \%$ (Georgia) to $48.1 \%$ (Azerbaijan). Many of the same factors were associated with occasional and frequent solitary drinking including being older, divorced/widowed, living alone, having financial difficulty and a lower level of social support. Both occasional and frequent solitary drinking was linked 
Table 1

Frequency of solitary drinking among male regular drinkers by sample characteristics in nine countries of the former Soviet Union.

\begin{tabular}{|c|c|c|c|c|c|c|c|}
\hline \multirow[t]{3}{*}{ Characteristic } & \multirow[t]{3}{*}{ Categories } & \multicolumn{6}{|c|}{ Frequency of solitary drinking" } \\
\hline & & \multicolumn{2}{|l|}{ Never } & \multicolumn{2}{|c|}{ Occasional } & \multicolumn{2}{|c|}{ Frequent } \\
\hline & & $N$ & $\%(95 \% \mathrm{CI})$ & $N$ & $\%(95 \% \mathrm{CI})$ & $N$ & $\%(95 \% \mathrm{CI})$ \\
\hline \multirow[t]{5}{*}{ Age (years) } & $18-29$ & 802 & $76.0(73.4-78.6)$ & 229 & $21.7(19.2-24.2)$ & 24 & $2.3(1.4-3.2)$ \\
\hline & $30-39$ & 569 & $73.2(70.1-76.3)$ & 179 & $23.0(20.1-26.0)$ & 29 & $3.7(2.4-5.1)$ \\
\hline & $40-49$ & 486 & $65.9(62.5-69.4)$ & 221 & $30.0(26.7-33.3)$ & 30 & $4.1(2.6-5.5)$ \\
\hline & $50-59$ & 364 & $60.7(56.8-64.6)$ & 190 & $31.7(27.9-35.4)$ & 46 & $7.7(5.5-9.8)$ \\
\hline & $\geq 60$ & 297 & $54.3(50.1-58.5)$ & 171 & $31.3(27.4-35.2)$ & 79 & $14.4(11.5-17.4)$ \\
\hline \multirow{3}{*}{ Education } & Tertiary & 718 & $70.9(68.1-73.7)$ & 250 & $24.7(22.0-27.3)$ & 45 & $4.4(3.2-5.7)$ \\
\hline & Secondary & 1541 & $67.8(65.8-69.7)$ & 616 & $27.1(25.3-28.9)$ & 117 & $5.1(4.2-6.1)$ \\
\hline & Less than secondary & 253 & $60.4(55.7-65.1)$ & 120 & $28.6(24.3-33.0)$ & 46 & $11.0(8.0-14.0)$ \\
\hline \multirow[t]{3}{*}{ Marital status } & Married/cohabiting & 1713 & $68.3(66.5-70.1)$ & 654 & $26.1(24.4-27.8)$ & 141 & $5.6(4.7-6.5)$ \\
\hline & Never married & 624 & $75.5(72.6-78.5)$ & 189 & $22.9(20.0-25.7)$ & 13 & $1.6(0.7-2.4)$ \\
\hline & Divorced or widowed & 173 & $46.6(41.5-51.7)$ & 145 & $39.1(34.1-44.1)$ & 53 & $14.3(10.7-17.9)$ \\
\hline \multirow{3}{*}{$\begin{array}{l}\text { Household } \\
\text { economic } \\
\text { situation }\end{array}$} & Good/very good & 572 & $70.4(67.3-73.6)$ & 213 & $26.2(23.2-29.3)$ & 27 & $3.3(2.1-4.6)$ \\
\hline & Average & 1498 & $69.3(67.4-71.3)$ & 554 & $25.6(23.8-27.5)$ & 109 & $5.0(4.1-6.0)$ \\
\hline & Bad/very bad & 420 & $59.7(56.1-63.4)$ & 215 & $30.6(27.2-34.0)$ & 68 & $9.7(7.5-11.9)$ \\
\hline \multirow[t]{2}{*}{ Living alone } & No & 2374 & $69.3(67.7-70.8)$ & 886 & $25.9(24.4-27.3)$ & 167 & $4.9(4.2-5.6)$ \\
\hline & Yes & 138 & $49.5(43.6-55.3)$ & 102 & $36.6(30.9-42.2)$ & 39 & $14.0(9.9-18.1)$ \\
\hline \multirow[t]{3}{*}{ Social support } & High & 2248 & $70.6(69.0-72.2)$ & 785 & $24.6(23.1-26.1)$ & 152 & $4.8(4.0-5.5)$ \\
\hline & Moderate & 100 & $49.5(42.6-56.4)$ & 81 & $40.1(33.3-46.9)$ & 21 & $10.4(6.2-14.6)$ \\
\hline & Low & 58 & $49.6(40.5-58.7)$ & 41 & $35.0(26.4-43.7)$ & 18 & $15.4(8.8-22.0)$ \\
\hline \multirow{3}{*}{$\begin{array}{l}\text { Self-rated } \\
\text { health }\end{array}$} & Good/very good & 1226 & $73.4(71.2-75.5)$ & 379 & $22.7(20.7-24.7)$ & 66 & $3.9(3.0-4.9)$ \\
\hline & Fair & 1032 & $65.1(62.7-67.4)$ & 464 & $29.3(27.0-31.5)$ & 90 & $5.7(4.5-6.8)$ \\
\hline & Poor/very poor & 248 & $56.4(51.7-61.0)$ & 140 & $31.8(27.5-36.2)$ & 52 & $11.8(8.8-14.8)$ \\
\hline \multirow[t]{2}{*}{ Location } & Urban & 1476 & $65.8(63.8-67.7)$ & 637 & $28.4(26.5-30.3)$ & 131 & $5.8(4.9-6.8)$ \\
\hline & Rural & 1042 & $70.8(68.5-73.1)$ & 353 & $24.0(21.8-26.2)$ & 77 & $5.2(4.1-6.4)$ \\
\hline
\end{tabular}

Abbreviations: $\mathrm{CI}$ confidence interval.

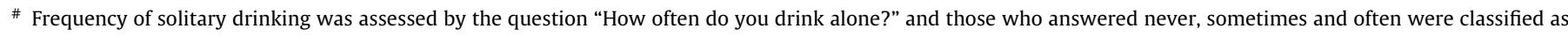
never, occasional and frequent solitary drinkers, respectively.

to problematic alcohol use, while occasional solitary drinking was associated with HED.

The present study confirmed findings from several previous studies that the prevalence of solitary drinking can be fairly high (Demers and Bourgault, 1996; Mäkelä et al., 2012). Moreover, even after adjustment for confounders, there were significant differences between the countries, with Azerbaijan and Georgia having the highest and lowest odds for occasional solitary drinking, respectively, while the highest and lowest odds for frequent solitary drinking were observed in Armenia and Moldova, respectively. It is possible that these country-wise differences might be related to differences in the drinking patterns and behaviours across these countries (Pomerleau et al., 2005) such as how much alcohol is drunk, when and where it is consumed or the circumstances associated with its consumption. Alternatively, previous research has suggested that other factors such as ethnicity (Neff, 1997) and religion (San José et al., 1999) are linked to differences in solitary drinking and it is possible that these or other factors might have also been important across our study countries.

Older age, being divorced/widowed, living alone, and having financial difficulty, were all associated with solitary drinking in the fSU countries. Earlier studies have also linked older age (Assanangkornchai et al., 2010; Grønkjær et al., 2010) and living alone (Demers and Bourgault, 1996) to solitary drinking, while there is some evidence that, compared to social drinkers, more solitary drinkers are divorced and widowed (Demers and Bourgault, 1996). A previous study has also indicated that male solitary drinkers may have lower levels of total household income compared to other types of alcohol drinkers (Martin and Casswell, 1987) which accords with our finding that both occasional and frequent solitary drinkers were more likely to report their household economic situation as bad or very bad. In addition, this study also showed that occasional solitary drinkers were more likely to be in poor health, while frequent solitary drinkers had lower levels of social support. Taken together, the overall portrait that emerges from the current study of male solitary drinkers in the fSU is one where they tend to be older, more isolated and are socially and economically disadvantaged.

The exact mechanism(s) underpinning the link between social and economic disadvantage and solitary drinking in the fSU is uncertain, although it can be speculated that those people with fewer network ties, and who lack socioeconomic resources, are more likely to have experienced major difficulties in recent years, especially given the unprecedented social and economic changes that occurred in the fSU countries in the wake of the collapse of communism, and the subsequent withdrawal of social safety nets that were previously relied upon (Field and Twigg, 2000). This might be important as research has shown that having a greater number of negative interpersonal experiences is linked to more solitary drinking (Mohr et al., 2001). It is also possible that these same people, who are experiencing greater difficulty, are using alcohol as a coping mechanism, which has previously been suggested as a motive for solitary drinking (Cooper et al., 1992). This supposition gains some support from earlier research in the fSU countries which has indicated that for certain people, alcohol is used in response to negative affect and stress (Abbott et al., 2006).

If drinking alone is a way of coping among those who are socially and economically disadvantaged, it might help explain the association we found between solitary drinking and problematic alcohol 
Table 2

Logistic regression analysis of factors associated with occasional and frequent solitary drinking among male regular drinkers in nine countries of the former Soviet Union.

\begin{tabular}{|c|c|c|c|c|c|c|c|c|c|}
\hline \multirow[t]{3}{*}{ Characteristics } & \multirow[t]{3}{*}{ Categories } & \multicolumn{4}{|c|}{ Occasional solitary drinking $(N=3241)^{\dagger}$} & \multicolumn{4}{|c|}{ Frequent solitary drinking $(N=2537)^{\ddagger}$} \\
\hline & & \multicolumn{2}{|l|}{ Univariable } & \multicolumn{2}{|l|}{ Multivariable } & \multicolumn{2}{|l|}{ Univariable } & \multicolumn{2}{|l|}{ Multivariable ${ }^{\mathbb{f}}$} \\
\hline & & OR $(95 \% \mathrm{CI})$ & $P$-value & OR $(95 \% \mathrm{CI})$ & $P$-value & OR $(95 \% \mathrm{CI})$ & $P$-value & OR $(95 \% \mathrm{CI})$ & $P$-value \\
\hline \multirow[t]{5}{*}{ Age (years) } & $18-29$ & 1.00 & & 1.00 & & 1.00 & & 1.00 & \\
\hline & $30-39$ & $1.13(0.90-1.43)$ & 0.293 & $1.08(0.82-1.41)$ & 0.599 & $1.62(0.90-2.90)$ & 0.106 & $0.94(0.50-1.78)$ & 0.847 \\
\hline & $40-49$ & $1.57(1.25-1.97)$ & $<0.001$ & $1.39(1.05-1.85)$ & 0.024 & $2.03(1.14-3.61)$ & 0.016 & $1.05(0.55-2.02)$ & 0.882 \\
\hline & $50-59$ & $1.85(1.46-2.35)$ & $<0.001$ & $1.62(1.20-2.21)$ & 0.002 & $4.10(2.40-7.01)$ & $<0.001$ & $2.11(1.12-3.97)$ & 0.020 \\
\hline & $\geq 60$ & $1.88(1.46-2.42)$ & $<0.001$ & $1.47(1.05-2.05)$ & 0.025 & $9.10(5.53-14.95)$ & $<0.001$ & $3.38(1.80-6.33)$ & $<0.001$ \\
\hline \multirow{3}{*}{ Education } & Tertiary & 1.00 & & 1.00 & & 1.00 & & 1.00 & \\
\hline & Secondary & $1.14(0.95-1.37)$ & 0.147 & $0.99(0.81-1.20)$ & 0.895 & $1.22(0.84-1.78)$ & 0.296 & $1.02(0.68-1.54)$ & 0.909 \\
\hline & Less than secondary & $1.35(1.03-1.78)$ & 0.030 & $1.05(0.77-1.43)$ & 0.774 & $2.97(1.88-4.71)$ & $<0.001$ & $1.69(0.98-2.91)$ & 0.060 \\
\hline \multirow[t]{3}{*}{ Marital status } & Married/cohabiting & 1.00 & & 1.00 & & 1.00 & & 1.00 & \\
\hline & Never married & $0.78(0.64-0.95)$ & 0.013 & $1.02(0.78-1.32)$ & 0.895 & $0.21(0.11-0.40)$ & $<0.001$ & $0.32(0.15-0.68)$ & 0.003 \\
\hline & Divorced or widowed & $2.11(1.64-2.72)$ & $<0.001$ & $1.50(1.10-2.05)$ & 0.011 & $3.31(2.26-4.85)$ & $<0.001$ & $1.39(0.79-2.44)$ & 0.248 \\
\hline \multirow[t]{3}{*}{ Household economic situation } & Good/very good & 1.00 & & 1.00 & & 1.00 & & 1.00 & \\
\hline & Average & $0.97(0.80-1.18)$ & 0.784 & $0.92(0.75-1.13)$ & 0.428 & $1.59(1.02-2.49)$ & 0.042 & $1.23(0.76-2.00)$ & 0.400 \\
\hline & Bad/very bad & $1.36(1.07-1.72)$ & 0.012 & $1.37(1.04-1.81)$ & 0.027 & $3.35(2.06-5.45)$ & $<0.001$ & $2.20(1.24-3.90)$ & 0.007 \\
\hline \multirow[t]{2}{*}{ Living alone } & No & 1.00 & & 1.00 & & 1.00 & & 1.00 & \\
\hline & Yes & $1.95(1.47-2.61)$ & $<0.001$ & $1.42(0.99-2.03)$ & 0.056 & $3.65(2.39-5.60)$ & $<0.001$ & $1.88(0.98-3.60)$ & 0.058 \\
\hline \multirow[t]{3}{*}{ Social support } & High & 1.00 & & 1.00 & & 1.00 & & 1.00 & \\
\hline & Moderate & $2.32(1.71-3.14)$ & $<0.001$ & $1.70(1.23-2.35)$ & 0.001 & $3.12(1.89-5.13)$ & $<0.001$ & $2.12(1.20-3.74)$ & 0.009 \\
\hline & Low & $2.13(1.41-3.22)$ & $<0.001$ & $1.28(0.81-2.02)$ & 0.290 & $4.59(2.60-8.10)$ & $<0.001$ & $2.46(1.22-4.98)$ & 0.012 \\
\hline \multirow[t]{3}{*}{ Self-rated health } & Good/very good & 1.00 & & 1.00 & & 1.00 & & 1.00 & \\
\hline & Fair & $1.43(1.21-1.68)$ & $<0.001$ & $1.37(1.13-1.65)$ & 0.001 & $1.63(1.15-2.31)$ & 0.006 & $0.98(0.65-1.46)$ & 0.903 \\
\hline & Poor/very poor & $1.81(1.42-2.32)$ & $<0.001$ & $1.62(1.19-2.19)$ & 0.002 & $3.97(2.64-5.98)$ & $<0.001$ & $1.28(0.76-2.16)$ & 0.350 \\
\hline \multirow[t]{2}{*}{ Location } & Urban & 1.00 & & 1.00 & & 1.00 & & 1.00 & \\
\hline & Rural & $0.81(0.69-0.95)$ & 0.010 & $0.87(0.73-1.04)$ & 0.127 & $0.83(0.61-1.13)$ & 0.230 & $0.72(0.51-1.03)$ & 0.072 \\
\hline \multirow[t]{9}{*}{ Country } & Armenia & $1.73(1.35-2.20)$ & $<0.001$ & $1.71(1.33-2.21)$ & $<0.001$ & $2.05(1.35-3.10)$ & 0.001 & $2.10(1.32-3.34)$ & 0.002 \\
\hline & Azerbaijan & $2.17(1.60-2.94)$ & $<0.001$ & $2.45(1.78-3.37)$ & $<0.001$ & $1.45(0.77-2.72)$ & 0.249 & $1.75(0.87-3.52)$ & 0.116 \\
\hline & Belarus & $1.13(0.93-1.37)$ & 0.233 & $1.15(0.94-1.41)$ & 0.188 & $0.79(0.52-1.21)$ & 0.276 & $0.92(0.58-1.45)$ & 0.723 \\
\hline & Georgia & $0.25(0.19-0.34)$ & $<0.001$ & $0.22(0.16-0.31)$ & $<0.001$ & $0.62(0.40--0.96)$ & 0.031 & $0.53(0.32-0.86)$ & 0.011 \\
\hline & Kazakhstan & $1.28(1.04-1.59)$ & 0.021 & $1.39(1.11-1.73)$ & 0.004 & $0.57(0.33-0.99)$ & 0.048 & $0.71(0.40-1.28)$ & 0.260 \\
\hline & Kyrgyzstan & $0.64(0.46-0.90)$ & 0.010 & $0.68(0.48-0.97)$ & 0.031 & $1.05(0.61-1.80)$ & 0.873 & $1.08(0.59-1.96)$ & 0.808 \\
\hline & Moldova & $0.82(0.66-1.01)$ & 0.067 & $0.75(0.59-0.94)$ & 0.012 & $0.72(0.47-1.12)$ & 0.150 & $0.51(0.31-0.84)$ & 0.008 \\
\hline & Russia & $1.24(1.03-1.48)$ & 0.021 & $1.20(1.00-1.45)$ & 0.054 & $1.61(1.18-2.20)$ & 0.003 & $1.63(1.16-2.29)$ & 0.005 \\
\hline & Ukraine & $1.12(0.91-1.39)$ & 0.270 & $1.10(0.89-1.37)$ & 0.385 & $1.00(0.66-1.51)$ & 0.984 & $0.88(0.56-1.39)$ & 0.575 \\
\hline
\end{tabular}

Abbreviations: OR odds ratio; Cl confidence interval.

Frequency of solitary drinking was assessed by the question "How often do you drink alone?" and those who answered sometimes and often were classified as occasional and frequent solitary drinkers, respectively.

$\dagger$ Frequent solitary drinkers were not included in the models.

₹ Occasional solitary drinkers were not included in the models.

T Mutually adjusted for all covariates in the models.

" Reference category is the overall grand mean. 
Table 3

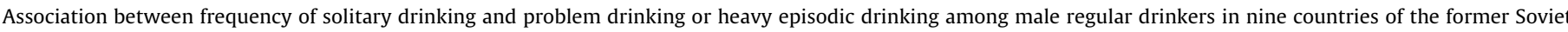
Union.

\begin{tabular}{|c|c|c|c|c|c|c|c|c|}
\hline \multirow[t]{3}{*}{ Solitary drinking\# } & \multicolumn{4}{|c|}{ Problem drinking ${ }^{\dagger}(N=3317)$} & \multicolumn{4}{|c|}{ Heavy episodic drinking ${ }^{\ddagger}(N=3427)$} \\
\hline & \multicolumn{2}{|l|}{ Univariable } & \multicolumn{2}{|l|}{ Multivariable } & \multicolumn{2}{|l|}{ Univariable } & \multicolumn{2}{|l|}{ Multivariable } \\
\hline & OR $(95 \% \mathrm{CI})$ & $P$-value & OR $(95 \% \mathrm{CI})$ & $P$-value & OR $(95 \% \mathrm{CI})$ & $P$-value & OR $(95 \% \mathrm{CI})$ & $P$-value \\
\hline Never & 1.00 & & 1.00 & & 1.00 & & 1.00 & \\
\hline Occasional & $2.10(1.79-2.46)$ & $<0.001$ & $2.08(1.75-2.47)$ & $<0.001$ & $1.33(1.14-1.56)$ & $<0.001$ & $1.25(1.05-1.48)$ & 0.011 \\
\hline Frequent & $3.29(2.41-4.50)$ & $<0.001$ & $3.27(2.33-4.58)$ & $<0.001$ & $0.71(0.53-0.97)$ & 0.031 & $0.77(0.55-1.07)$ & 0.117 \\
\hline
\end{tabular}

Abbreviations: OR odds ratio; $\mathrm{CI}$ confidence interval.

^ Multivariable analysis adjusted for age, education, marital status, household economic situation, living alone, social support, self-rated health, location, and country.

$\dagger$ CAGE problem drinking was based on 4 questions: Have you ever felt you should cut down on your drinking?; Have people annoyed you by criticizing your drinking?;

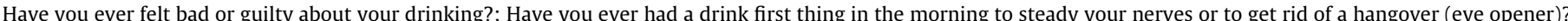

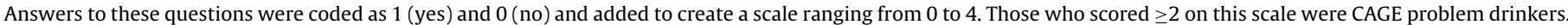

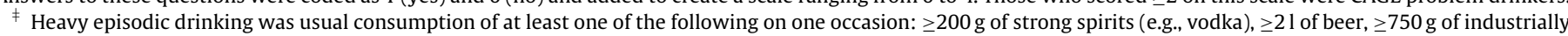
produced wine.

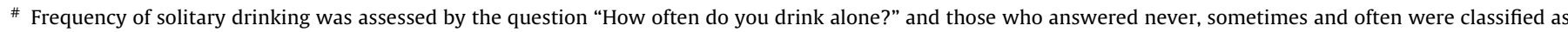
never, occasional and frequent solitary drinkers, respectively.

use-a finding which accords with earlier research that linked solitary drinking with CAGE problem drinking (Victorio-Estrada and Mucha, 1997). Specifically, Cooper et al. (1995) have suggested that those who use alcohol to cope may lack other ways of coping, and that the use of alcohol might itself further erode coping capacity and increase dependency on alcohol. This may explain not only why drinking to cope, especially when alone, is associated with greater alcohol use (Mohr et al., 2001), but also, why solitary drinking has been previously linked to higher frequency drinking (Christiansen et al., 2002; Demers and Bourgault, 1996). Further, the finding that solitary drinking is more prevalent among alcohol dependent individuals is also understandable against this backdrop (Assanangkornchai et al., 2000).

\subsection{Limitations}

There are several limitations that should be mentioned. First, the use of a filter question in the HITT survey meant that we were not able to examine solitary drinking among those who consume alcohol infrequently. This means that our findings are not representative of all male drinkers in these countries, although previous research has also focused on this phenomenon solely among male regular drinkers (Neff, 1997). Second, all the information was self-reported and we had no way of verifying the reports of solitary drinking. For example, social disapproval attached to this practice may lead to under-reporting in some settings (Bourgault and Demers, 1997). Third, the question we used to measure solitary drinking did not define the frequency of drinking occasions in precise quantitative terms. It is possible that 'sometimes' and 'often' could have been interpreted differently depending on the setting. Fourth, we had no information on certain aspects of solitary drinking that might be important for understanding this phenomenon such as where solitary drinking occurred or its relation with drinking in other contexts. Previous research has shown for example, that only a small percentage of individuals (5\%) drink exclusively in solitary settings (Bourgault and Demers, 1997). The absence of information on solitary drinkers' social drinking meant that we were not able to determine the totality of drinking behaviour (Demers and Bourgault, 1996) or the role of solitary drinking in it, which might be important for future interventions to limit this behaviour. Finally, since this was a cross-sectional study, the directionality of the observed associations could not be established. It is possible that various demographic and socioeconomic factors (divorce, low social support, poor economic situation) might facilitate/inhibit solitary drinking. Alternatively, solitary drinking might be a marker for alcohol abuse/dependence that leads to marital disruption, fewer social connections and a worse economic situation.

\section{Conclusion}

This study has shown that with the exception of Georgia, male solitary drinking is relatively common throughout the countries of the fSU and is linked to being older and experiencing social and economic disadvantage. Those regular drinkers who drink alone are also more likely to engage in hazardous drinking. This suggests that not only the drinking pattern, but also the drinking situation/context may be important in understanding problematic alcohol use in the countries in this region. Future public health efforts to reduce hazardous drinking should thus recognise the drinking context as being a potentially important intervention site, while societal-level policies that reduce socioeconomic disadvantage and foster greater social inclusiveness might help reduce this form of alcohol consumption and its detrimental effects.

\section{Author disclosures}

Role of funding source

This work was supported by the European Union's 7th Framework Programme, project HEALTH-F2-2009-223344. The European Commission cannot accept any responsibility for any information provided or views expressed. AK's work was supported by the Miguel Servet contract financed by the CP13/00150 project, integrated into the National $\mathrm{R}+\mathrm{D}+\mathrm{I}$ and funded by the ISCIII-General Branch Evaluation and Promotion of Health Research-and the European Regional Development Fund (ERDF).

Contributors

AS designed the study, analysed the data and wrote the main body of the text; AK analysed the data and contributed to the writing of the text; BR, AM, KK, and MM contributed to the writing of the text. All authors read and approved the submission of the final manuscript to Drug and Alcohol Dependence.

\section{Conflict of interest}

No conflict declared.

\section{Acknowledgments}

We are grateful to all members of the HITT study who participated in the co-ordination and organisation of data collection for this paper. 


\section{References}

Abbott, P.A., Turmov, S., Wallace, C., 2006. Health world views of post-Soviet citizens. Soc. Sci. Med. 62, 228-238.

Andreev, E., Bogoyavlensky, D., Stickley, A., 2013. Comparing alcohol mortality in tsarist and contemporary Russia: is the current situation historically unique? Alcohol Alcohol. 48, 215-221.

Assanangkornchai, S., Sam-Angsri, N., Rerngpongpan, S., Lertnakorn, A., 2010. Patterns of alcohol consumption in the Thai population: results of the National Household Survey of 2007. Alcohol Alcohol. 45, 278-285.

Assanangkornchai, S., Saunders, J.B., Conigrave, K.M., 2000. Patterns of drinking in Thai men. Alcohol Alcohol. 35, 263-269.

Bourgault, C., Demers, A., 1997. Solitary drinking: a risk factor for alcohol-related problems? Addiction 92, 303-312.

Christiansen, M., Vik, P.W., Jarchow, A., 2002. College student heavy drinking in social contexts versus alone. Addict. Behav. 27, 393-404.

Cooper, M.L., Frone, M.R., Russell, M., Mudar, P., 1995. Drinking to regulate positive and negative emotions: a motivational model of alcohol use. J. Pers. Soc. Psychol. 69, 990-1005.

Cooper, M.L., Russell, M., Skinner, J.B., Windle, M., 1992. Development and validation of a three-dimensional measure of drinking motives. Psychol. Assess. 4, 123-132.

Cox, W.M., Klinger, E., 1988. A motivational model of alcohol use. J. Abnorm. Psychol. 97, 168-180.

Creswell, K.G., Chung, T., Clark, D.B., Martin, C.S., 2014. Solitary alcohol use in teens is associated with drinking in response to negative affect and predicts alcohol problems in young adulthood. Clin. Psychol. Sci. 2, 602-610.

Demers, A., Bourgault, C., 1996. Changing society, changing drinking: solitary drinking as a non-pathological behaviour. Addiction 91, 1505-1516.

Field, M.G., Twigg, J.L. (Eds.), 2000. Russia's Torn Safety Nets: Health and Social Welfare during the Transition. Macmillan, Basingstoke.

Footman, K., Roberts, B., Stickley, A., Kizilova, K., Rotman, D., McKee, M., 2013. Smoking cessation and desire to stop smoking in nine countries of the former Soviet Union. Nicotine Tob. Res. 15, 1628-1633.

Gaunekar, G., Patel, V., Rane, A., 2005. The impact and patterns of hazardous drinking amongst male industrial workers in Goa, India. Soc. Psychiatry Psychiatr. Epidemiol. 40, 267-275.

Gonzalez, V.M., 2012. Association of solitary binge drinking and suicidal behavior among emerging adult college students. Psychol. Addict. Behav. 26, 609-614.

Gonzalez, V.M., Collins, R.L., Bradizza, C.M., 2009. Solitary and social heavy drinking suicidal ideation, and drinking motives in underage college drinkers. Addict. Behav. 34, 993-999.

Greenfield, T.K., Room, R., 1997. Situational norms for drinking and drunkenness: trends in the US adult population, 1979-1990. Addiction 92, 33-47.

Grønkjær, M., Curtis, T., De Crespigny, C., Delmar, C., 2013. Drinking contexts and the legitimacy of alcohol use: findings from a focus group study on alcohol use in Denmark. Scand. J. Public Health 41, 221-229.

Grønkjær, M., Vinther-Larsen, M., Curtis, T., Grønbæk, M., Nørgaard, M., 2010. Alcohol use in Denmark: a descriptive study on drinking contexts. Addict. Res. Theory 18, 359-370.
Leon, D.A., Saburova, L., Tomkins, S., Andreev, E., Kiryanov, N., McKee, M., Shkolnikov V.M., 2007. Hazardous alcohol drinking and premature mortality in Russia: a population based case-control study. Lancet 369, 2001-2009.

Mäkelä, P., Tigerstedt, C., Mustonen, H., 2012. The Finnish drinking culture: change and continuity in the past 40 years. Drug Alcohol. Rev. 31, 831-840.

Martin, C., Casswell, S., 1987. Types of male drinkers: a multivariate study. J. Stud. Alcohol. 48, 109-118.

Mohr, C.D., Armeli, S., Tennen, H., Carney, M.A., Affleck, G., Hromi, A., 2001. Daily interpersonal experiences, context, and alcohol consumption: crying in your beer and toasting good times. J. Pers. Soc. Psychol. 80, 489-500.

Murphy, A., Roberts, B., Kenward, M.G., De Stavola, B.L., Stickley, A., McKee, M., 2014a. Using multi-level data to estimate the effect of social capital on hazardous alcohol consumption in the former Soviet Union. Eur. J. Public Health 24, 572-577.

Murphy, A., Roberts, B., Ploubidis, G.B., Stickley, A., McKee, M., 2014b. Using multilevel data to estimate the effect of an 'alcogenic' environment on hazardous alcohol consumption in the former Soviet Union. Health Place 27, 205-211.

Neff, J.A., 1997. Solitary drinking, social isolation, and escape drinking motives as predictors of high quantity drinking, among Anglo, African American and Mexican American males. Alcohol Alcohol. 32, 33-41.

Nordlund, S., Østhus, S., 2013. What is alcohol abuse? Attitudes to drinking in seven European countries. Addict. Res. Theory 21, 402-409.

Pomerleau, J., McKee, M., Rose, R., Haerpfer, C.W., Rotman, D., Tumanov, S., 2005. Drinking in the Commonwealth of Independent States-evidence from eight countries. Addiction 100, 1647-1668.

Pomerleau, J., McKee, M., Rose, R., Haerpfer, C.W., Rotman, D., Tumanov, S., 2008. Hazardous alcohol drinking in the former Soviet Union: a cross-sectional study of eight countries. Alcohol Alcohol. 43, 351-359.

Roberts, B., Stickley, A., Gilmore, A.B., Danishevski, K., Kizilova, K., Bryden, A., Rotman, D., Haerpfer, C., McKee, M., 2013. Knowledge of the health impacts of smoking and public attitudes towards tobacco control in the former Soviet Union. Tob. Control 22, e12.

San José, B., Bongers, I.M., Garretsen, H.F., 1999. Drinking patterns and attitudes toward drinking in the late-middle-aged. Subst. Use Misuse 34, 1085-1100.

Stickley, A., Koyanagi, A., Roberts, B., Richardson, E., Abbott, P., Tumanov, S., McKee, M., 2013. Loneliness: its correlates and association with health behaviours and outcomes in nine countries of the former Soviet Union. PLoS ONE 8, e67978.

Stickley, A., Leinsalu, M., Andreev, E., Razvodovsky, Y., Vågerö, D., McKee, M., 2007. Alcohol poisoning in Russia and the countries in the European part of the former Soviet Union, 1970-2002. Eur. J. Public Health 17, 444-449.

Stickley, A., Razvodovsky, Y., McKee, M., 2009. Alcohol mortality in Russia: a historical perspective. Public Health 123, 20-26.

Victorio-Estrada, A., Mucha, R.F., 1997. The Inventory of Drinking Situations (IDS) in current drinkers with different degrees of alcohol problems. Addict. Behav. 22 557-565.

World Health Organization, 2011. Global Status Report on Alcohol and Health. WHO, Geneva.

Zaridze, D., Lewington, S., Boroda, A., Scélo, G., Karpov, R., Lazarev, A., Konobeevskaya, I., Igitov, V., Terechova, T., Boffetta, P., Sherliker, P., Kong, X., Whitlock, G., Boreham, J., Brennan, P., Peto, R., 2014. Alcohol and mortality in Russia: prospective observational study of 151,000 adults. Lancet 383, $1465-1473$ 